\section{Looking at the Stars}

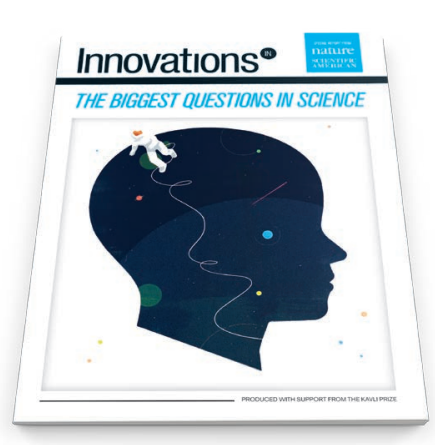

"WE ARE ALL IN THE GUTTER, BUT SOME OF US are looking at the stars," Oscar Wilde wrote. Ever since an early human sat by the glowing embers of a fire on a winter night, as others fell asleep and the camp quietened, we have pondered the mysteries of existence. What are those points of light studding the sky? What are these movements within my belly? Where did this life come from? What is life? How do I protect this being from all harm?

Such questions have occupied not only ordinary humans through the ages but also philosophers and, later, scientists. In recent centuries we have learned so much — and such marvelous things — about the worlds around and within us that it may sometimes seem that no nook is left unexplored, no miracles left for us to unravel. The truth is, though, that every new discovery leads us to ever deeper questions. We know what the stars are, but their motion defies explanation. We can look into the farthest crannies of the universe, but the more we see, the more we suspect that we may never, truly, understand it all. We have a good idea of how the body works, but the mind remains elusive. We know what life is but not where that first spark came from. We can observe unimaginably minute objects, but the more we try to control them, the more they seem to evade our grasp.

This special report on "The Biggest Questions in Science," which is being published in both Scientific American and Nature, is sponsored by the Kavli Prize. It was produced independently by Scientific American and Nature editors, who have sole responsibility for all the editorial content. Beyond the choice to sponsor this particular topic, the Kavli Prize had no input about the content of the articles in this package.

\section{Madhusree Mukerjee Senior Editor}

S3 What Is Spacetime?

Physicists believe that at the tiniest scales, space emerges from quanta. What might these building blocks look like?

By George Musser

\section{S6 What Is Dark Matter?}

An elusive substance that permeates the universe exerts many detectable gravitational influences yet eludes direct detection.

By Lisa Randall

S8 What Is Consciousness? Scientists are beginning to unravel a mystery that has long vexed philosophers. By Christof Koch

\section{S13 How Did Life Begin?}

Untangling the origins of organisms will require experiments at the tiniest scales and observations at the vastest. By Jack Szostak

\section{S14 GRAPHIC: Origins of Life}

\section{S16 What Are the Limits of Manipulating Nature?}

By reaching down into the quantum world, scientists are hoping to gain more control over matter and energy. By Neil Savage

\section{S20 How Much Can We Know?}

The reach of the scientific method is constrained by the limitations of our tools and the intrinsic impenetrability of some of nature's deepest questions. By Marcelo Gleiser

\section{EDITORIAL}

EDITOR IN CHIEF AND SENIOR VP Mariette DiChristina

MANAGING EDITOR Curtis Brainard

CHIEF FEATURES EDITOR Seth Fletcher

SENIOR EDITOR
Madhusree Mukerjee
CHIEF SUPPLEMENTS EDITOR, NATURE
Herb Brody
CREATIVE DIRECTOR
Michael Mrak

SENIOR GRAPHICS EDITOR Jen Christiansen

COPY DIRECTOR

Maria-Christina Keller

COPY EDITORS

Daniel C. Schlenoff, Aaron Shattuck

\author{
MANAGING PRODUCTION EDITOR \\ Richard Hunt \\ PREPRESS AND QUALITY MANAGER \\ Silvia De Santis \\ PUBLISHER AND VP \\ Jeremy A. Abbate
}

